\title{
Simulation Aspects of the High Pressure Die Casting Process
}

\author{
M. BuBEnKó1 ${ }^{1}$ D. MOLNÁR ${ }^{2}$ \\ University of Miskolc, Faculty of Material Science and Engineering, Foundry Institute \\ E-mail: ${ }^{1}$ ontbm@uni-miskolc.hu, ${ }^{2}$ daniel.molnar@uni-miskolc.hu
}

Keywords: Computer simulation, Control Volume Method, High Pressure Die Casting

Abstract. High pressure die casting (HPDC) is a manufacturing process for producing accurately dimensioned, sharply defined, smooth or textured surface metal parts. It is accomplished by injecting liquid metal at fast velocity and under high pressure into reusable steel dies. Compared to other casting processes, die casting is at the top end of both velocity and pressure. The high velocity translates into a very turbulent flow condition. The process is often described as the shortest distance between raw material and the finished product.

High pressure die casting is particularly suitable for high production rates, and it is applied in several industrial fields; actually, approximately half of the world production of light metal castings is obtained by this technology. In the high pressure die casting of aluminium alloys, cold-chamber die casting machines are typically used, in which the metal injection system is only in contact with the molten metal for a short period. Liquid metal, maintained in a holding furnace at a desired temperature, is generally ladled into the shot sleeve for each cycle. Several operations are involved in the whole high pressure die casting process, from the spraying and blowing out the die to the opening and closing of the die, even if the main steps are the filling of the shot chamber, the injection of the metal into the die, the solidification and the further extraction of the casting, see Fig.1. [1]

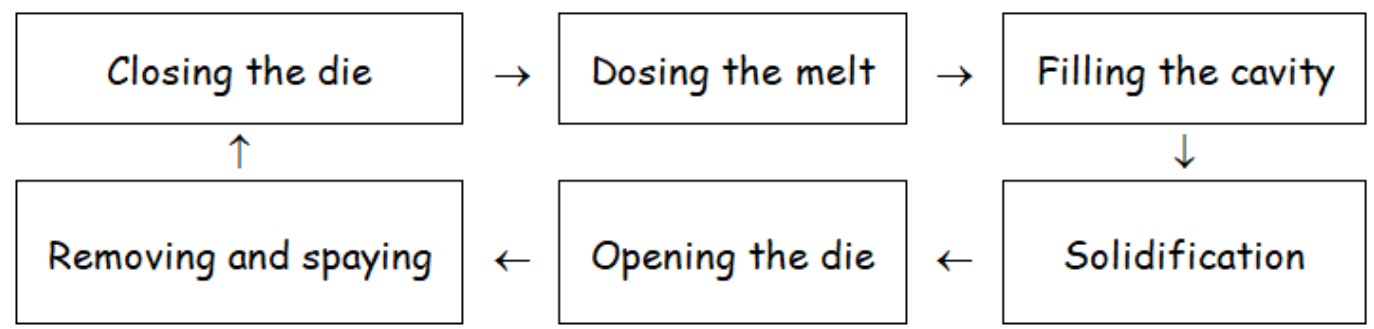

Figure 1. The process chain of high pressure die casting

In high pressure die casting the liquid melt is charged into the shot sleeve according to the chamber fill ratio. The time of metal charging affects cycle time, productivity and profitability. The target of charging is the air displacement from the chamber through the casting cavity, so the piston moves forward with a controlled slow velocity and the melt accumulates on the frontal face of it. During the movement of the piston waves are developing in the melt and moves along the sleeve and displaces air. The first phase is over when the melt fills the whole shot sleeve cavity which indicates a switching 
sign. This switching sing starts the second phase when the movement of the piston is fast and the cavity fills totally until the piston abrupt stops and hit the liquid melt. At this moment the kinetic energy transforms into pressure energy and frictional thermal energy. In the third phase the entrapped air bubbles and the shrinkage cavities are compressed with a high pressure during solidification.

Therefore, the HPDC is a complex process, not only due to the phase transformation the metal undergoes when solidifying in the die. In fact:

- The production of high-pressure die castings begins by first pouring liquid metal into a steel shot sleeve.

- A piston accelerates quickly and transports the molten metal into a steel die, resulting in metal velocities between $30-80 \mathrm{~m} / \mathrm{s}$.

- The subsequent extremely short filling time (50-100 ms) guarantees the perfect filling of complexshaped castings with thin wall thickness before metal solidification.

- During solidification the metal contracts, leaving eventually shrinkage porosity in the casting.

- The process tries to overcome these physical phenomena by pressing liquid metal into the die using several atmospheres. $[2,3]$

The graphical illustration of a cold-chamber die casting machine can be seen in Fig.2.

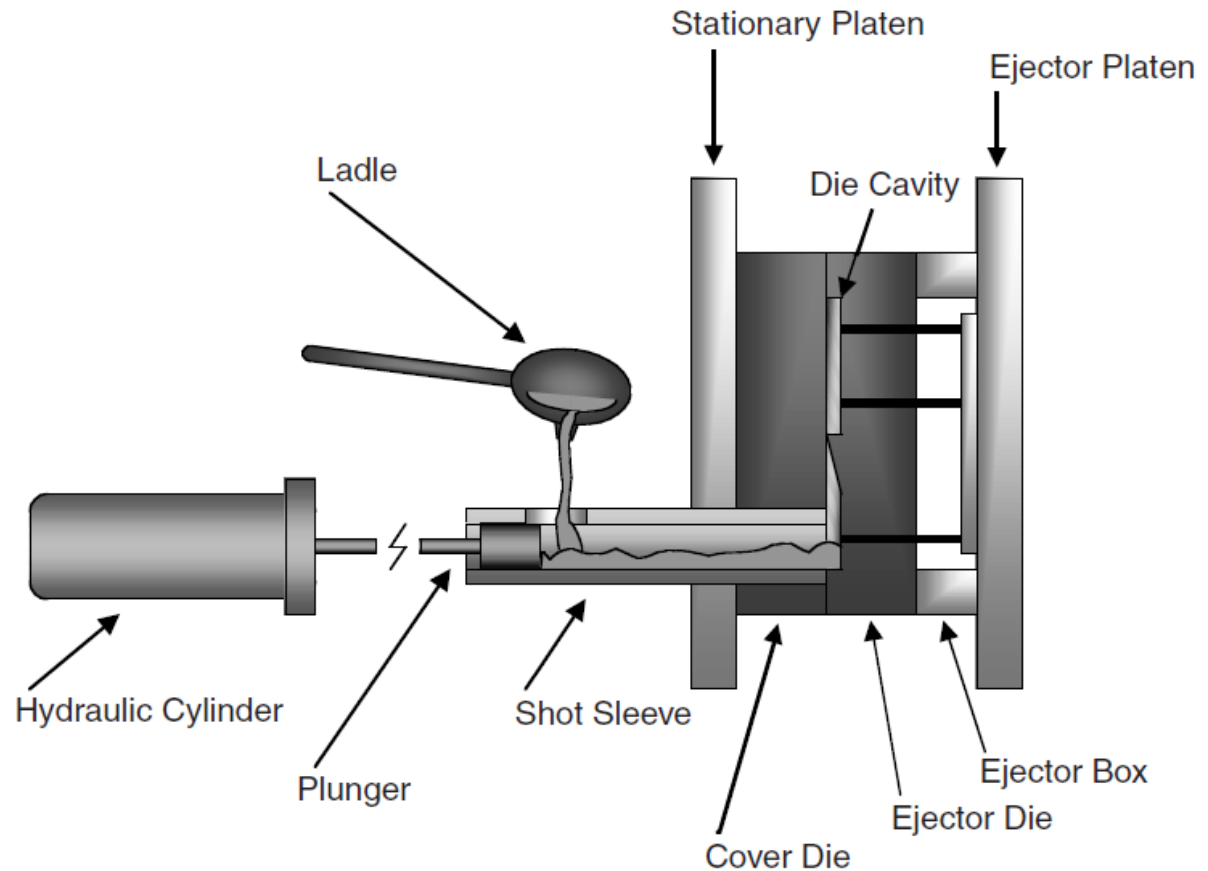

Figure 2. Graphical illustration of a cold-chamber die casting machine

Because of the complexity of the high pressure die casting process, several technological parameters should be observed for fulfilling of the requirements of the customer, such as surface quality, mechanical properties, dimensional accuracy, etc. To be able to minimize the scrap rate, computer simulation is an important tool for the engineers and scientists by solving technological problems on the following way (see Fig.3). [4] 


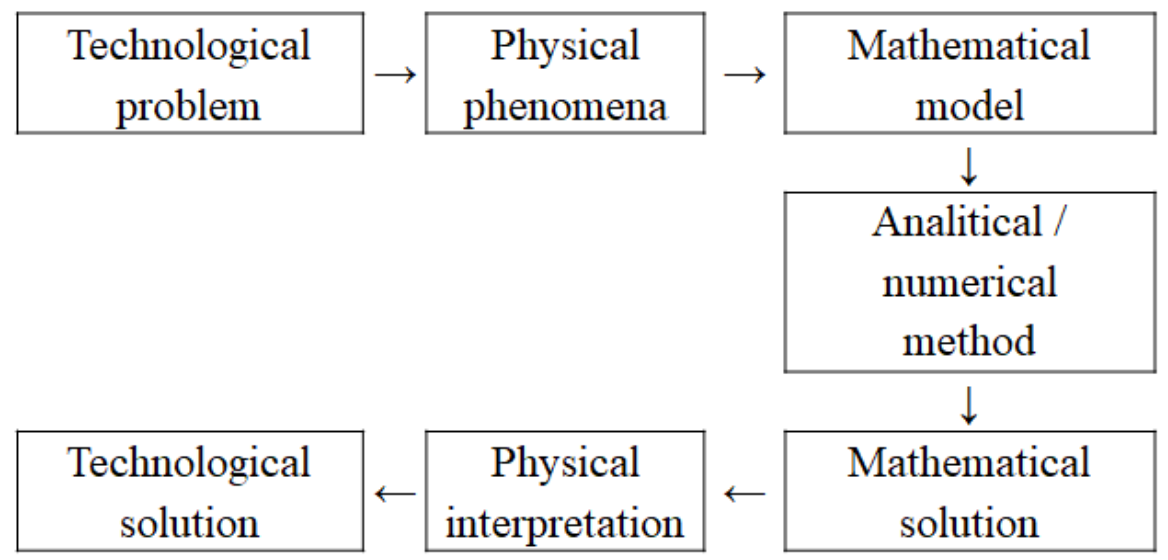

Figure 3. Solution of a technological problem by simulation

\section{Application of casting simulation}

The aspects of the application of casting process simulation can be detailed as follows:

- Quickly analyse various proposed design alternatives to make decisions.

- Allows designers to optimize designs by ensuring the desired material properties.

- Allows for the comprehensive development of the casting.

- Identify defect potential early using filling and solidification simulations.

- Eases the communication between company departments.

- Shortens ramp-up times of production processes, as the number of prototypes and trial runs can be reduced.

- Leads to efficient processes, reduced cycle times, less down time, and rework time.

- Reduces production costs related to the volume of re-melt, reduced energy consumption, reduced scrap rates and improved tool life.

- Utilization leads to a faster and more reliable achievement of customer requirements.

- Introducing the casting process to unfamiliar customer.

- Explaining how design elements affect casting soundness.

- Aiding conversion from other processes.

\section{Flow at the metal fill front}

Although an understanding of the bulk liquid metal flow is often useful, the flow of the metal at the fill front is of most concern. Three distinct metal fill fronts are encountered in die casting processes:

- planar fill,

- nonplanar fill,

- atomized fill. 
Traditional thinking regarding fluid flow tends to assume that the liquid metal fill front progresses as a uniform plane throughout the die. A graphical illustration of this phenomenon is shown in Fig. 4.

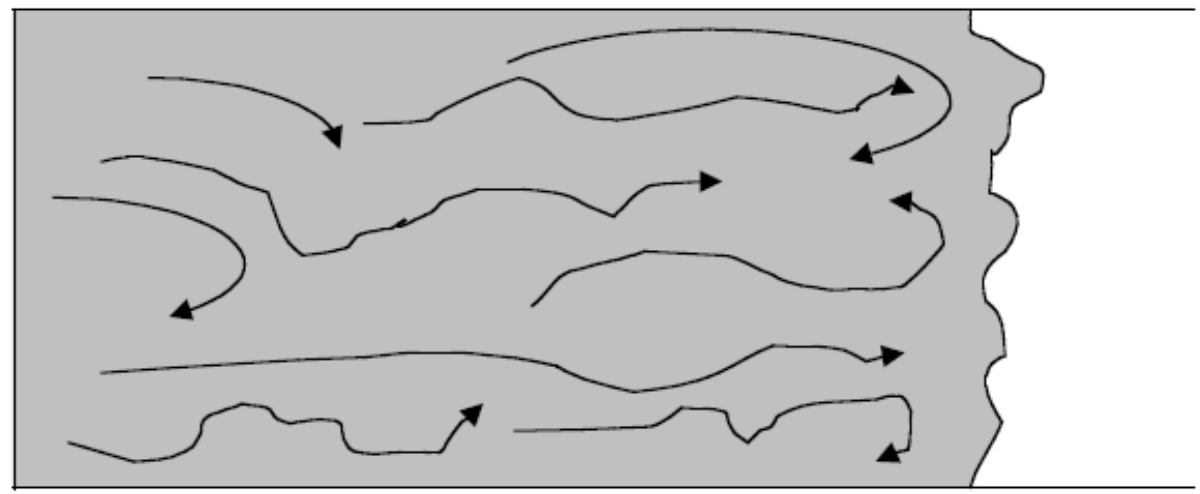

Direction of Metal Flow

Figure 4. Graphical illustration of planar flow

This form of planar fill does occur in some casting processes. However, planar fill during die casting occurs only under very specific conditions. The complex geometries of most components cause the liquid metal fill front to separate. When planar filling of the die cavity does occur, gases trapped within the die are pushed ahead of the metal fill front. In Fig.5. the progression of a die cavity filling with a planar metal front is shown. By locating vents and overflows at the farthest point from the gate, gas entrapment can be virtually eliminated.
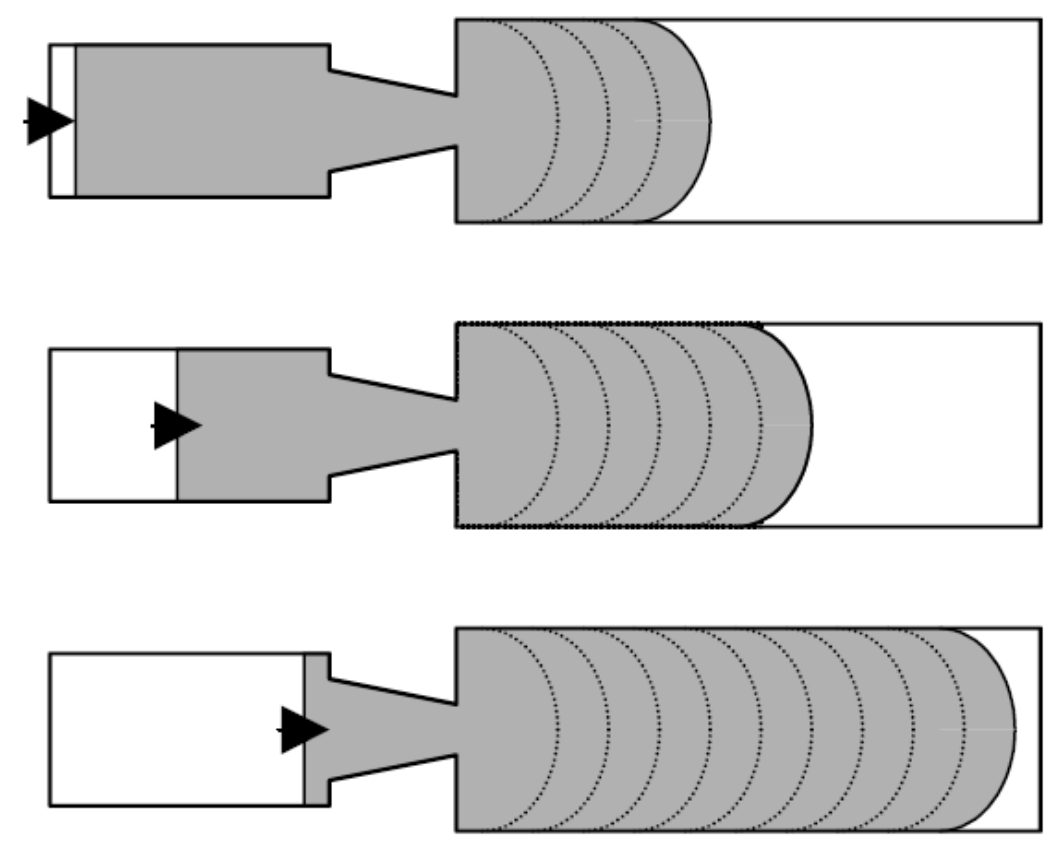

Figure 5. Graphical illustration showing the progression of a die cavity filling with a planar metal front

Nonplanar flow is also observed in many casting processes. Unlike planar metal flow, the fill front is not uniform, as shown in Fig.6. 


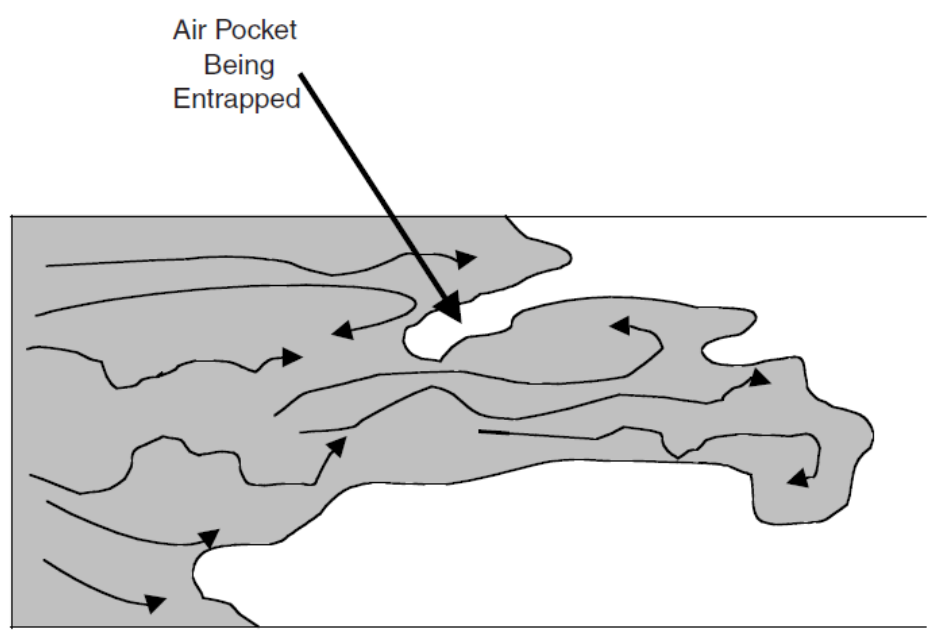

Direction of Metal Flow

Figure 6. Graphical illustration of non-planar flow

Often metal fronts converge and surround a pocket of air, resulting in entrapped gases in the component being produced. When die casting, nonplanar fill often results in the die cavity being filled from the outside inward. This fill behavior is shown in Fig.7. the metal stream begins to fan out after entering the die cavity. As the metal reaches the far side of the die cavity, gases are entrapped as the fill front doubles over on itself. The metal front continues to travel along the surface of the die, filling the cavity from the outside inward. This results in additional pockets of entrapped gas.
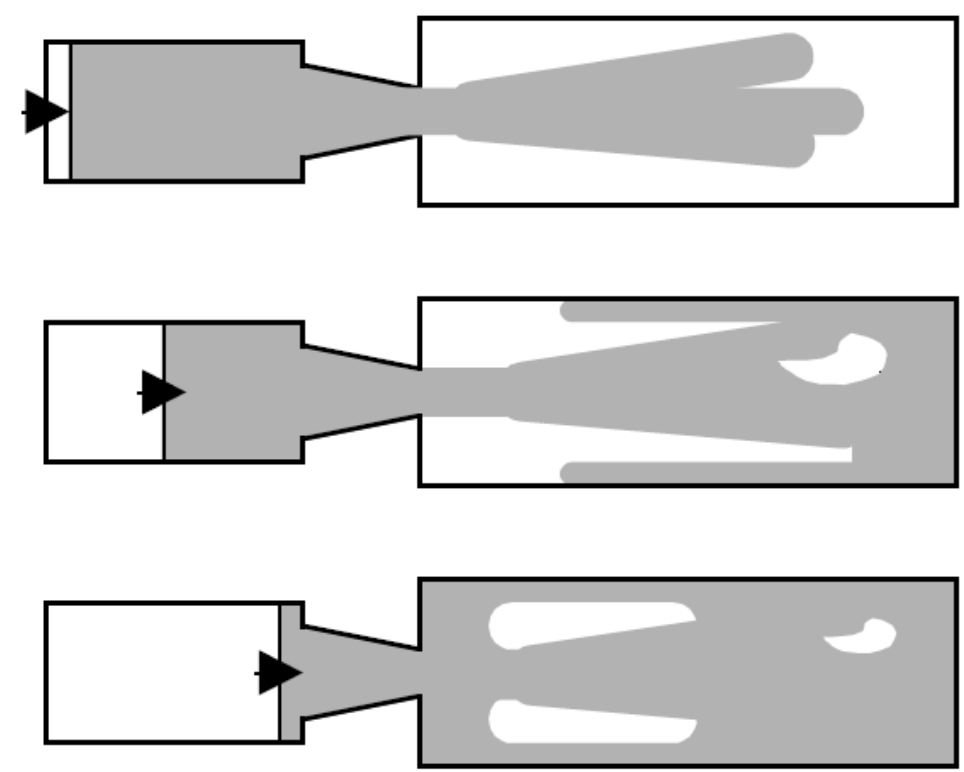

Figure 7. Graphical illustration showing the progression of a die cavity filling with a nonplanar fill

When liquid metal is traveling at high velocities through a very small gate, the fill front breaks down, resulting in atomization. This phenomenon is illustrated in Fig.8. 


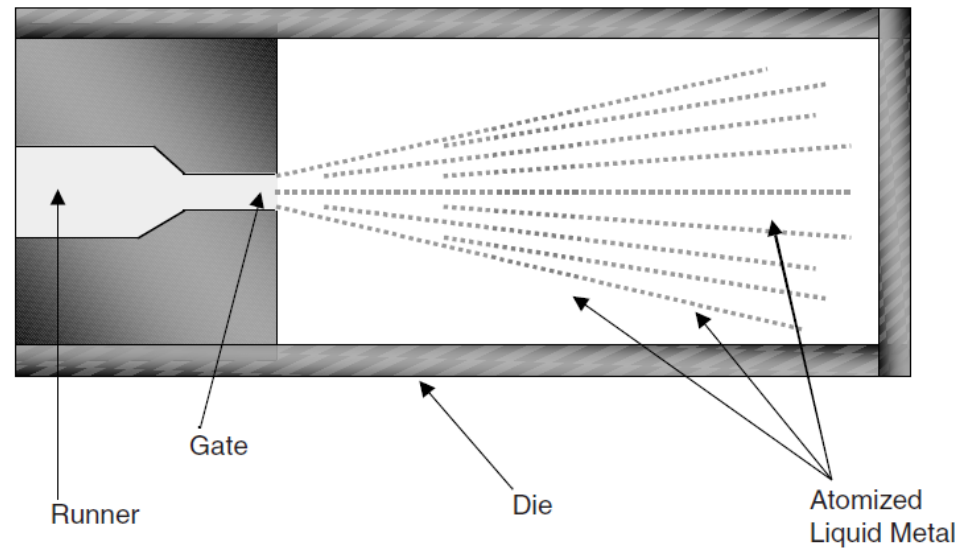

Figure 8. Illustration showing atomized flow typical in conventional die casting

Due to the high pressure and velocities, the metal becomes in effect an aerosol, spraying into the die cavity. Shown in Fig.9. is the progression of die fill, which occurs with atomized metal flow. Liquid metal is sprayed into the die. Filling occurs from the surface of the cavity inward. Typically, the first metal to enter the die strikes the far side of the die cavity and solidifies immediately. [2]
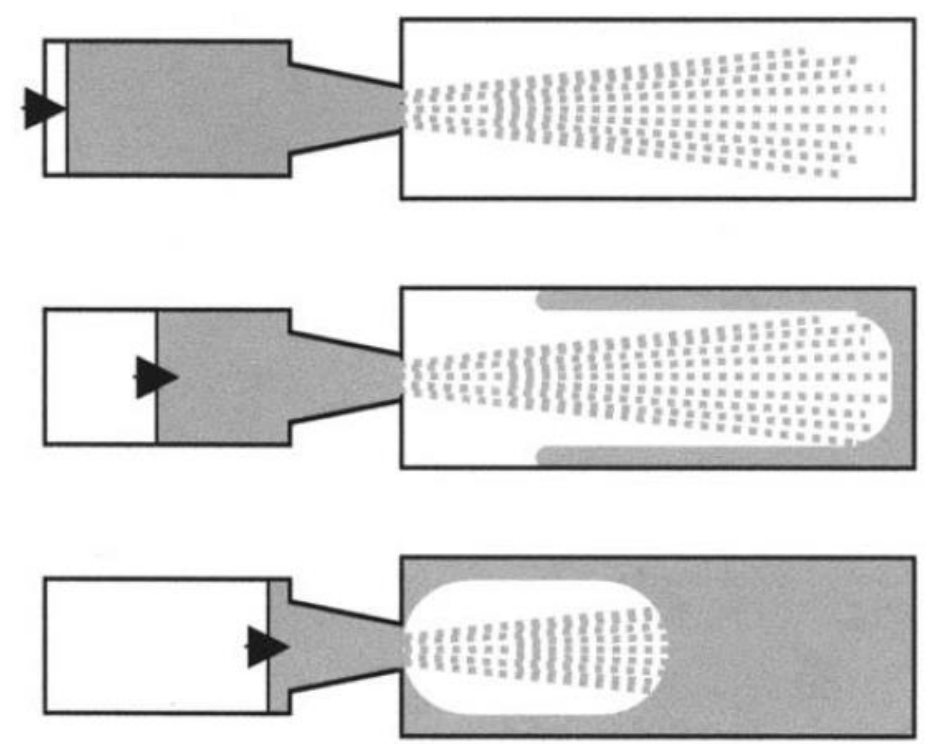

Figure 9. Graphical illustration of die fill with atomized metal flow in conventional die casting

Over the last decades vast improvements in computer hardware and software technology have made complex simulations of physical phenomena possible. Today engineers and designers have available an ever-growing and continually refined set of tools to aid in product development. Mathematical models using both finite element and finite difference techniques have been developed to simulate various manufacturing processes. Specific to high integrity die casting processes, mathematical models have been developed to simulate several elements, including mould filling, air entrapment, liquid metal surface tracking, solidification thermodynamics, material properties after solidification, shrinkage porosity and part distortion. 


\section{Gating system calculations}

The calculation of the gating system can be done by concerning the following parameters. First the socalled casting part data must be defined:

- Number of cavities in the die.

- The projected area of the entire casting.

- Mass or volume of one part (as cast) without overflows and without the gating system.

- Mass or volume of the overflows at a single part per cavity.

- Biscuit thickness of the geometry.

The following geometrical values must be defined:

- The smallest wall thickness of the cast part on the flow path of the melt. This parameter is used for the calculation of the maximum die cavity filling time. Thin-walled boundary regions, e.g. flanges, supports, small ribs, through which no further die cavity areas are filled or fed, should not be considered here.

- The surface area of one part.

The die cavity filling time is the time required to completely fill the cavity and the overflows of one part. To obtain an estimate of the maximum admissible cavity filling time, the solidification of the metal during die filling is considered. Complete filling of the cavity is possible only when the metal remains liquid during the filling process, i.e. when the solid fraction of the alloy does not exceed a certain maximum value. This value must be specified: 20 percent if a good surface quality is required, and 30 percent otherwise. It applies to casting sections with the smallest wall thickness, i.e. with the shortest solidification time. The solidification rate, and therefore also the maximum filling time, depend on the initial temperature of the die cavity surface and on the temperature of the metal entering the cavity. A value lower than the temperature in the holding furnace should be assumed for the metal temperature, since the metal has already cooled down in the chamber.

The calculation of the gate dimensions must be done knowing the actual casting geometry. An increase of the gate thickness may reduce shrinkage porosity, because feeding in the intensification stage will then be more effective. For pressure tight parts, the gate thickness should be chosen as large as possible. If the gate is too thin, it may freeze off even before the cavity has been completely filled, particularly in the case of magnesium alloys. For aluminum and magnesium alloys the gate thickness should not be under $0.8 \mathrm{~mm}$, for zinc alloys not under $0.3 \mathrm{~mm}$. If possible, the gate should extend over an entire side of the cast part.

The actual value of the piston diameter is an important factor of the gating system calculation. For cold chamber machines the length of the injection chamber can also be specified. The chamber length must be smaller than the maximum piston stroke of the machine. The filling ratio of the chamber, corresponding to the given shot volume must be calculated. Low filling ratios may cause considerable air entrapment during the $1^{\text {st }}$ phase stage, which results in an increased gas porosity of the cast parts. To avoid this, a lower piston velocity, i.e a longer duration of the $1^{\text {st }}$ phase stage would be required, 
which, on the other hand, increases the amount of metal solidifying in the chamber. In this respect, filling ratios lower than $40 \%$ should be avoided. [5]

The actual inflow cross-section of the runner must be defined. Inflow cross-section means the crosssectional area of the start section, i.e. close to the biscuit or nozzle. When designing the runner system, the following guidelines should be considered:

- The runner cross-sectional area should decrease towards the gate. This results in a better flow pattern and reduces entrapped air.

- At the transition to the gate the runner cross-section should be approximately twice as large as the gate cross-section.

- Every change of the runner direction should be accompanied by a reduction of the cross-sectional area by a factor of about $1+0.5 \sin a$, where a is the angle between the directions.

- The runner thickness should be at least $5 \mathrm{~mm}$. As a rule of thumb, the runner should be at least five times thicker than the gate.

\section{Simulation of the fluid flow}

Fluid flow plays an important role for the production of sound castings. Mould filling is the first step of every casting process and for many castings, mould filling determines the quality of the final product by excessive turbulence, air or gas entrapment, premature solidification, form erosion. During solidification buoyancy effects, segregation of alloy components, feeding flow are the examples of fluid flow phenomena that can take place. Modelling of the fluid flow is required if the above phenomena need to be taken into account.

In order to be able to model the mould filling properly, the following equations must in general be solved:

- The three momentum equations (momentum conservation) together with a suitable constitutive law relating stresses and velocities for incompressible, Newtonian fluids.

- The continuity equation (mass conservation).

- The energy equation (energy conservation).

Important phenomena that should be taken into account are e.g. temperature dependent viscosity and the tracking of free surfaces. These non-linear phenomena are often taken into account in an explicit manner in the numerical formulation. This means that very small steps should be taken. It should be noted that for especially thin-walled castings, surface tension could also play an important role. This adds yet another non-linearity to the fluid flow analysis.

Fluids are described as substances capable of flowing and conforming to the shape of containing vessels. In equilibrium conditions, fluids cannot sustain tangential, or shear forces. Fluids can be classified as liquids or gases, the main difference between the two being that liquids are usually only slightly compressible and gases are always compressible. Liquids occupy a definite volume forming the free surface, whereas gases expand to fill all the available volume. Matter is not continuous but discrete, made of molecules, but its properties are averages over a large number of molecules. On macroscopic scales, fluids can be treated like a continuum. The Knudsen number decides if the 
continuum models apply for a particular purpose. The Knudsen number (Kn) is defined as the ratio of a mean free path of molecules to the characteristic linear dimension of the problem. Usually it is assumed that below $\mathrm{Kn}=0.01$ continuum models always apply. Fluid flow, in this range of Knudsen number, is described by the Navier-Stokes equations with the no-slip boundary conditions. For the higher values of Knudsen number, up to about 0.1, the boundary conditions of the N-S Navier-Stokes equations must be modified. For even higher values of Knudsen number the Boltzmann equations should be used. [4]

\section{Acknowledgments}

"The described article/presentation/study was carried out as part of the EFOP-3.6.1-16-2016-00011 "Younger and Renewing University - Innovative Knowledge City - institutional development of the University of Miskolc aiming at intelligent specialisation" project implemented in the framework of the Szechenyi 2020 program. The realization of this project is supported by the European Union, cofinanced by the European Social Fund."

\section{References}

[1] F. Bonollo et al. (2015) High-Pressure Die-Casting: Contradictions and challenges. JOM The Journal of The Minerals, Metals \& Materials Society.

[2] E.J. Vinarcik (2003) High Integrity Die Casting Processes. New York, Wiley.

[3] ASM Metals Handbook, Casting, Materials Park, OH, ASM International, 1990

[4] J. Hattel (2005) Fundamentals of Numerical Modelling of Casting Processes, Polyteknisk, Lyngby.

[5] Forcasts Software Manual, Arbeitsgemeinschaft Metallguss GmbH, Aalen, 2012 